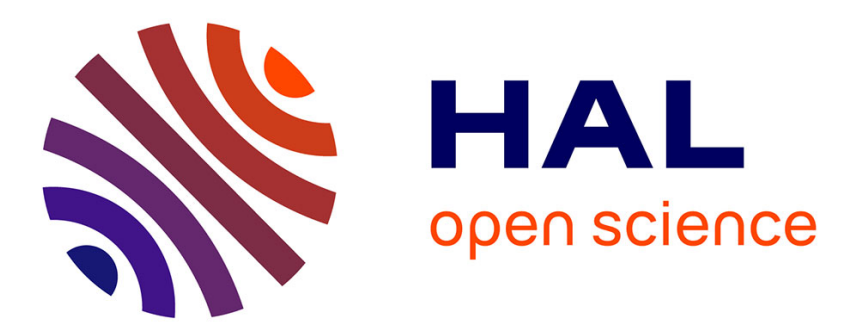

\title{
Experimental study on the effects of big particles physical characteristics on the hydraulic transport inside a horizontal pipe
}

Salah Zouaoui, Hassane Djebouri, Kamal Mohammedi, Sofiane Khelladi, Aomar Ait Aider

\section{To cite this version:}

Salah Zouaoui, Hassane Djebouri, Kamal Mohammedi, Sofiane Khelladi, Aomar Ait Aider. Experimental study on the effects of big particles physical characteristics on the hydraulic transport inside a horizontal pipe. Chinese Journal of Chemical Engineering, 2016, 24 (2), pp.317-322. 10.1016/j.cjche.2015.12.007 . hal-02438067

\section{HAL Id: hal-02438067 https://hal.science/hal-02438067}

Submitted on 14 Jan 2020

HAL is a multi-disciplinary open access archive for the deposit and dissemination of scientific research documents, whether they are published or not. The documents may come from teaching and research institutions in France or abroad, or from public or private research centers.
L'archive ouverte pluridisciplinaire HAL, est destinée au dépôt et à la diffusion de documents scientifiques de niveau recherche, publiés ou non, émanant des établissements d'enseignement et de recherche français ou étrangers, des laboratoires publics ou privés. 
Fluid Dynamics and Transport Phenomena

\title{
Experimental study on the effects of big particles physical characteristics on the hydraulic transport inside a horizontal pipe
}

\author{
Salah Zouaoui ${ }^{1, *}$, Hassane Djebouri ${ }^{1}$, Kamal Mohammedi ${ }^{2}$, Sofiane Khelladi ${ }^{3}$, Aomar Ait Aider ${ }^{1}$ \\ ${ }^{1}$ LMSE Laboratory, Mouloud Mammeri University of Tizi-Ouzou, P.O. Box 17 RP15000, Algeria \\ 2 LEMI Laboratory MESO, M'Hamed Bougara University of Boumerdes, 35000, Algeria \\ 3 DynFluid Laboratory, Arts et Metiers ParisTech, 151 boulevard de l'Hôpital, 75013 Paris, France
}

\begin{abstract}
A B S T R A C T
This paper presents an experimental study of the physical characteristic effects of large particles on hydraulic transport in a horizontal pipe. The particles are spherical and are large with respect to the diameter of the pipe $(8 \%, 10 \%, 16 \%$ and $25 \%)$. Experiments were done to test the important parameters in solid transport (pressure, velocity, etc.). As a result, the relationship between the pressure gradient forces and the mixture velocity was substantially different from the pure liquid flow. However, in a single-phase flow a monotonous behavior of the pressure drop curve is observed, and the curve of the solid particle flow attains its minimum at the critical velocity. The regimes are characterized with differential pressure measurements and visualizations.
\end{abstract}

\section{Introduction}

During these last decades, the demand of mineral materials from emerging countries strongly increased, causing the exploitation of new deposits. For this reason, several firms have recently launched a subsea mining project study, and the main task was to estimate the pressure drop of solid-liquid mixture in the flow line for various flow regimes. In this case, the circuit would have various and complex shapes, including vertical, horizontal ones, potentially bends, and S-shapes. [1]:

In general, solid transport is divided into three major flow patterns

(1) Pseudo-homogeneous or homogeneous flow and heterogeneous flow.

(2) Heterogeneous and sliding bed flow (or moving bed flow).

(3) Saltation and stationary bed flow.

In a pseudo-homogeneous flow case, the particles are distributed almost uniformly over the pipe cross-section and moved at a very high velocity. When the flow velocity of the particles decreases, the heterogeneous flow pattern occurs if there is a concentration gradient in the direction perpendicular to the pipe axis. Most of particles are carried out in the lower part of the pipe cross-section.

\footnotetext{
* Corresponding author.

E-mail addresses: zouaouisalah@ummto.dz,zouaoui_salah2003@yahoo.fr (S. Zouaoui).
}

Transporting solid particles in a fluid flow is very complex. Many researchers have tried to create a mathematical model in order to predict the head losses in slurry transport. Such as the models of Zandi [2], Turian et al. [3], Doron et al. [4], Doron and Barnea [5], Wilson and Pugh [6], Matousek [7], Bratland [8], and references therein. Lahiri and Ghanta [9] proposed a hybrid support vector regression-genetic algorithm approach to predicting the pressure drop of solid-liquid slurry flow. Recently, Edelin et al. [10] reported an experimental investigation of the transport of fluids composed of water and small size polypropylene particles, in order to study the transport of floating particles, also to determine the conditions that minimize the energy consumed by installations designed to this type of flow. These models enabled a fast and a global approach of the transported solid quantity in fluid flows, but they are generally approximate [11]. A predictive model for transporting large particles in vertical pipes was proposed and ratified on a set of experimental data, based on the work of Newitt et al. [12], Richardson and Zaki [13], Xia et al. [14], and Yoon et al. [15]. In horizontal pipes, the prediction of the flow patterns and pressure gradient known as a complex problem is treated via experimental correlations. Some of them are restricted to one or two flow patterns [16-18]. However, different authors [12,19-21] claim to apply these correlations for all flow patterns of liquid-solid systems. Miedema [22,23] proposed a new head loss model for slurry transport in the heterogeneous regime. This model shows resemblance with the Durand and Condolios [24] model. However the influence of the pipe diameter is much less matching the experimental results in larger pipes.

Many parameters are needed to describe the solid transport, such as water flow rate and solid particles, particle density and diameter, and 
the pressure drop along the pipe. This last is considered to be the mainly important parameter in solid-liquid flow. Most investigations carried out concerns only the very small ratio of particle to pipe diameter and low solid concentration. In this present study, an experimental investigation is conducted in a small scale to identify the effects of physical characteristics of big particles on the hydraulic transport in horizontal pipe. Moreover, influence of concentration, size and density of particles on the pressure drop, and mixture velocity above which the bed starts to move (critical velocity) are highlighted. Also, this work allows one to understand the blocking problem of the pipelines transporting water-solid mixture.

\section{Experimental Device}

\subsection{Test loop}

We performed a series of tests with the experimental loop shown in Fig. 1, and the different materials used are described below. We focused on the liquid-solid flow in a horizontal rigid pipe of length $L=2 \times 2 \mathrm{~m}$ and diameter $D=60 \mathrm{~mm}$. This tube carries a $180^{\circ}$ horizontal curve with $30 \mathrm{~cm}$ of diameter curvature. The test loop composed with a pump to supply the circuit with clear water and an injection system for solid particles. The particles fall down by gravity through a flexible tube connecting the bottom of particle tank to the main duct via a buffer zone. The last one, situated between the two valves is divided into three compartments of known capacity, allows us to determine the mean solid flow rate. The flow rate of injected particles into the pipe is adjusted by the lower valve (Fig. 1). Globally the particles flow is relatively stable and uniform, since we are dealing with a mean particles flow rate through measurement of time elapsed between opening and closure of the lower valve. The mixture arrives finally in a system to separate the solid from the liquid. This system consists of a first tank with a filter to recover the solid particles and allows only water to pass to the second tank. In order to realize a closed circuit for water, the second tank is connected to a pump which delivers the water into the circuit (Fig. 1).

\subsection{Particles and pipe}

The circuit is constructed with Plexiglas tube to allow the visualization of the flow. The calibrated beads of alumina (Umicore, Alumina Degussit $92 \%$, with a relative size dispersion of $10 \%$ ), and glass (SiLi, SiLibeads type M, with a relative dispersion of size of $4 \%$ ) are used [11]. The particles are relatively large, with size up to $25 \%$ of the pipe diameter. Their physical and geometrical characteristics are summarized in Fig. 2.

\subsection{Control parameters}

To masseur the flow parameters, we need some necessary measuring instruments. The water flow rate is measured using an electromagnetic flow meter (KROHNE Optiflux 2000), and adjusted using a pump's variator. The flow rate of solids is controlled by a device designed and realized in the laboratory. Optical measurements are also performed with a high-speed camera (Optronis CamRecord600). Typically 1000 images are recorded with a resolution of $1280 \times 1024$ pixels at a frame rate of $500 \mathrm{~Hz}$. The flow is illuminated backwards with a LED plate from Phlox, and the pressure drop is measured using two differential pressure sensors (VEGADIF65, VEGA, Germany).

The aim of the present work is to measure the pressure drops in different parts of the test loop as a function of solid concentration and mixture velocity. The parameters that are adjusted with experimental means are the volumetric flow rates of liquid $\left(Q_{l}\right)$ and of solids $\left(Q_{s}\right)$. To present the results we define the mixture velocity $\left(U_{\mathrm{m}}\right)$ and the delivered concentration $(C)$ as follows:

$U_{\mathrm{m}}=\frac{Q_{l}+Q_{S}}{S}$

$C=\frac{Q_{s}}{Q_{s}+Q_{l}}$

where $S$ is the cross-section area of the pipe, and the mixture velocity $\left(U_{\mathrm{m}}\right)$ presents a volumetric average of the velocities of each phase.

The pressure drops $(G)$ are expressed in terms of hydraulic gradients (meters of water column per meter of pipe):

$G=\frac{\Delta P}{\rho_{\mathrm{e}} g L}$

where $\rho_{\mathrm{e}}$ is the water density equal $1000 \mathrm{~kg} \cdot \mathrm{m}^{-3}$ and $L$ the distance between the pressure taps equal to $1.4 \mathrm{~m}$.

\section{Results and Discussion}

The thick black line in all figures stands for the measured hydraulic gradient with pure water flowing $(C=0 \%)$. The Reynolds number is $10^{5}$ and the flow is fully turbulent and the estimated rugosity is $20 \mu \mathrm{m}$. We observe inside the pipe that the pressure drop and the

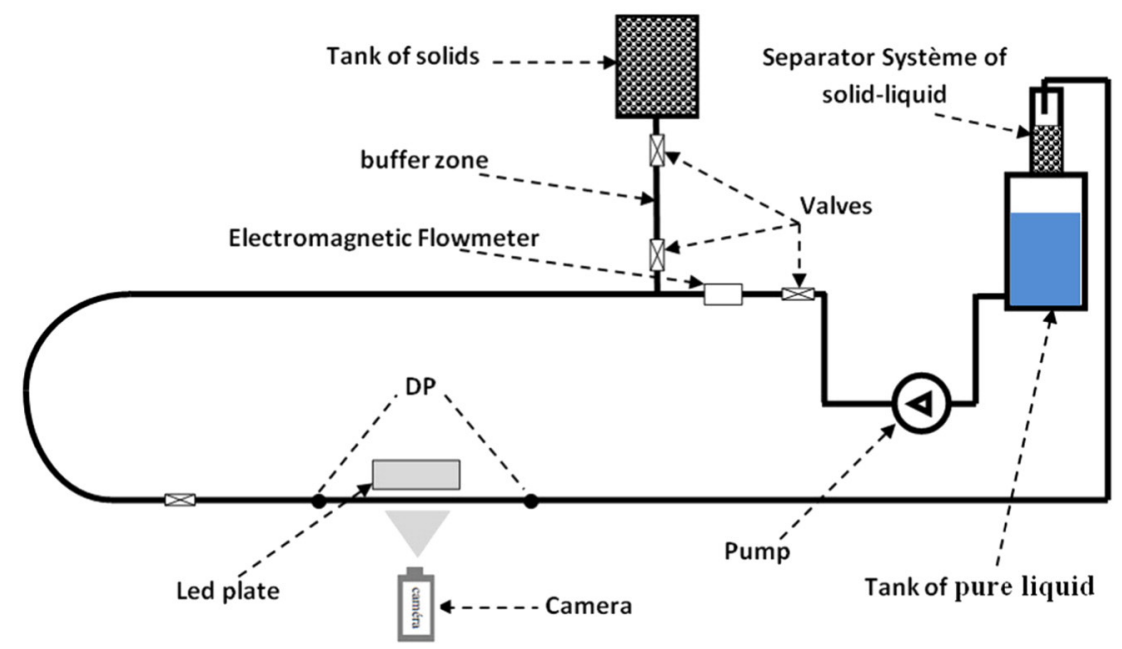

Fig. 1. Sketch of test loop. 

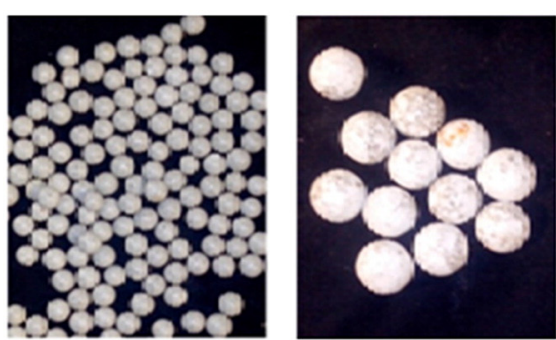

Alumina beads

Diameter: $6 \mathrm{~mm}$ and $15 \mathrm{~mm}$ Specific mass: $3650 \mathrm{~kg} \cdot \mathrm{m}^{-3}$
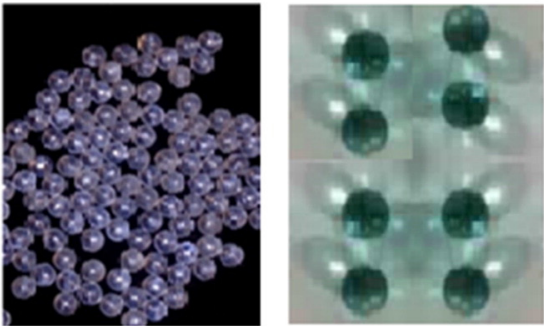

Glass beads

Diameter: $5 \mathrm{~mm}$ and $10 \mathrm{~mm}$

Specific mass: $2500 \mathrm{~kg} \cdot \mathrm{m}^{-3}$

Fig. 2. Physical characteristics of the calibrated beads.

mixture speed start to increase with quadratic rate, and the curve has the form:

$\Delta P=\frac{\lambda \rho U_{\mathrm{m}}^{2}}{D} L$

where the friction coefficient $\lambda$ is calculated by the Colebrook formula.

All curves in this study present the evolution of the hydraulic gradient as a function of the mixture speed for different particles types (alumina and glass) with different size and concentration. We see that for all the speed flow, the pressure drop is much higher than in the case of clear water. Moreover, the pressure drop curve does not vary monotonically with the mixture velocity. Following the definition of Doron et al. [4], the mixture velocity corresponding to the minimum hydraulic gradient is called the critical velocity $\left(U_{\mathrm{c}}\right)$.

Some pictures taken for the glass beads of diameter $10 \mathrm{~mm}$ at $C=10 \%$, are presented in Fig. 3 for different velocities. It shows that the flow regimes vary with the mixture speed: at low mixture speed we see the presence of a compact stationary bed at the bottom of the pipe (Fig. 3a); around the critical velocity $\left(U_{c}\right)$ we observe a compact moving bed (Fig. 3b); at high speed, as we can see also a pseudohomogeneous dispersed flow (Fig. 3c).

\subsection{Effects of concentration of alumina and glass particles}

This subsection is devoted to the comparison of the pressure drop curves with various concentrations and identical physical characteristics of the beads (density, size).

The effects of the concentration are shown in the Figs. 4 to 7.

From Figs. 4 to 7, we note that the increase in the delivered concentration leads to an increase in the pressure drop. Furthermore, the change in the concentration seems to increase only slightly the critical velocity (Fig. 4). Please note that with $5 \%$ concentration in most figures the pressure curves crosses the pure water curve $(C=0 \%)$ in Figs. 5 to 7 , due to the measurements errors.

The curvature of the pressure drop evolution in solid-liquid flow is due to the various flow regimes in horizontal pipe. At high mixture

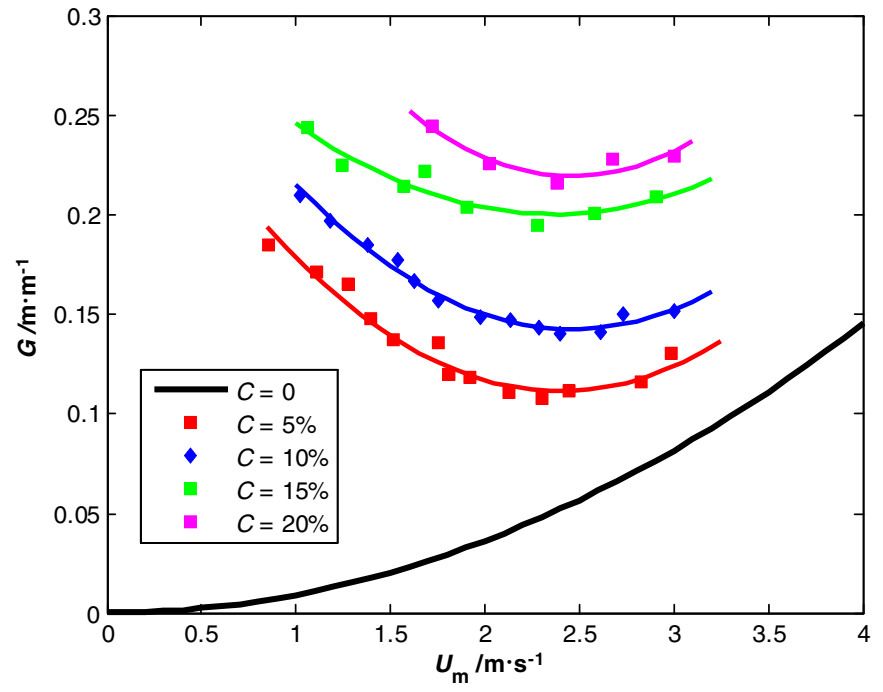

Fig. 4. Hydraulic gradient versus speed mixture. Alumina's concentration effect of $6 \mathrm{~mm}$ size.

velocities $\left(U_{\mathrm{m}}>U_{\mathrm{c}}\right)$, where the particles are suspended, the pressure drop is usually somewhat higher than that of the carrier liquid (water). We are in pseudo-homogeneous dispersed flow with a vertical concentration gradient (Fig. 3c). Reduction of the mixture velocity $\left(U_{\mathrm{m}} \approx U_{\mathrm{c}}\right)$, the concentration of particles in the bottom of the pipe reaches the compactness limit, leads to a moving bed formation (Fig. 3b) and to pressure drops much higher than those of the pure water. For even lower speeds $\left(U_{\mathrm{m}}<U_{\mathrm{c}}\right)$, a stationary bed is formed below a moving bed (Fig. 3a). So there are two or three layers.

For the case of alumina beads of $6 \mathrm{~mm}$, density $\rho_{\mathrm{al}}=3650 \mathrm{~kg} \cdot \mathrm{m}^{-3}$, and delivered concentration $C=5 \%$, the magnitude of the minimal pressure drop at the critical velocity $U_{\mathrm{c}} \simeq 2.3 \mathrm{~m} \cdot \mathrm{s}^{-1}$ is $G_{\mathrm{c}} \simeq 0.11 \mathrm{~m} \cdot \mathrm{m}^{-1}$ (Fig. 4).

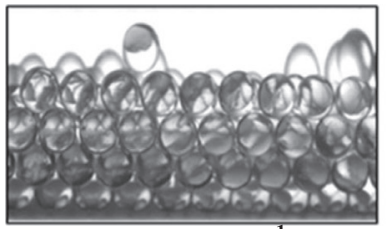

a)

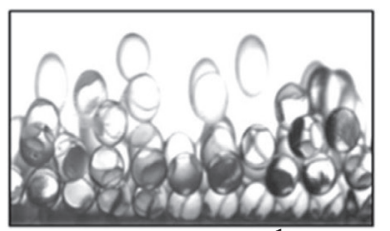

b) $\quad U_{\mathrm{m}}=2.3 \mathrm{~m} \cdot \mathrm{s}^{-1}$

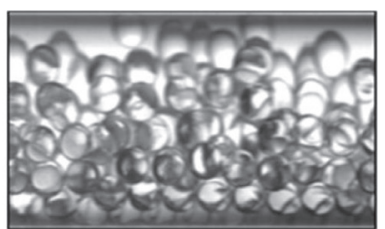

c) $\quad U_{\mathrm{m}}=\mathbf{3} \mathrm{m} \cdot \mathrm{s}^{-1}$

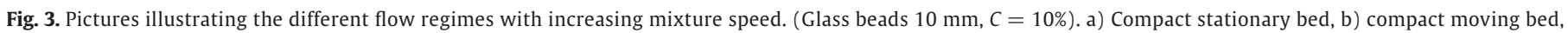
c) pseudo-homogeneous dispersed flow. 


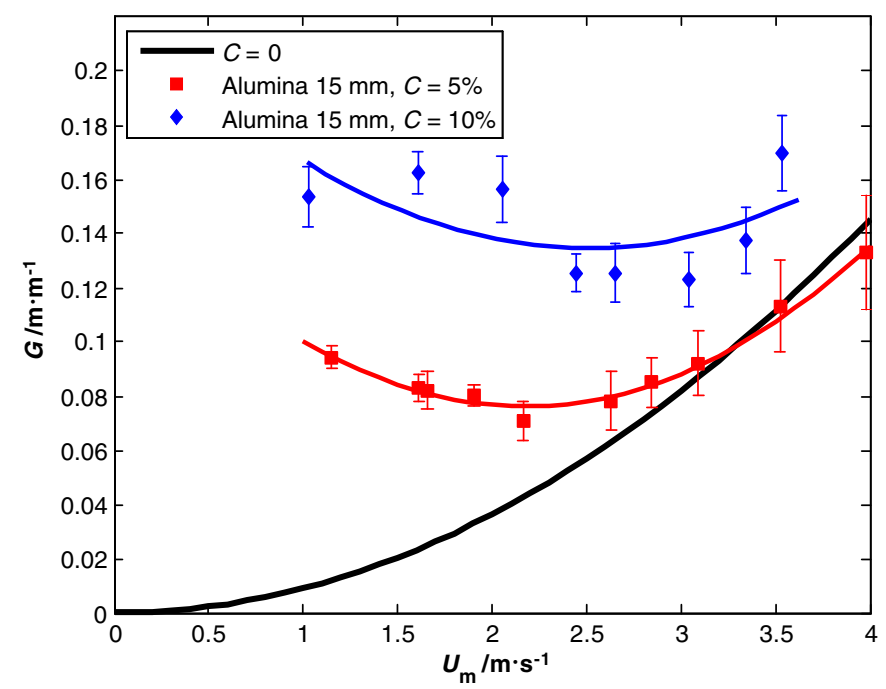

Fig. 5. Hydraulic gradient versus speed mixture. Alumina's concentration effect of $15 \mathrm{~mm}$ size.

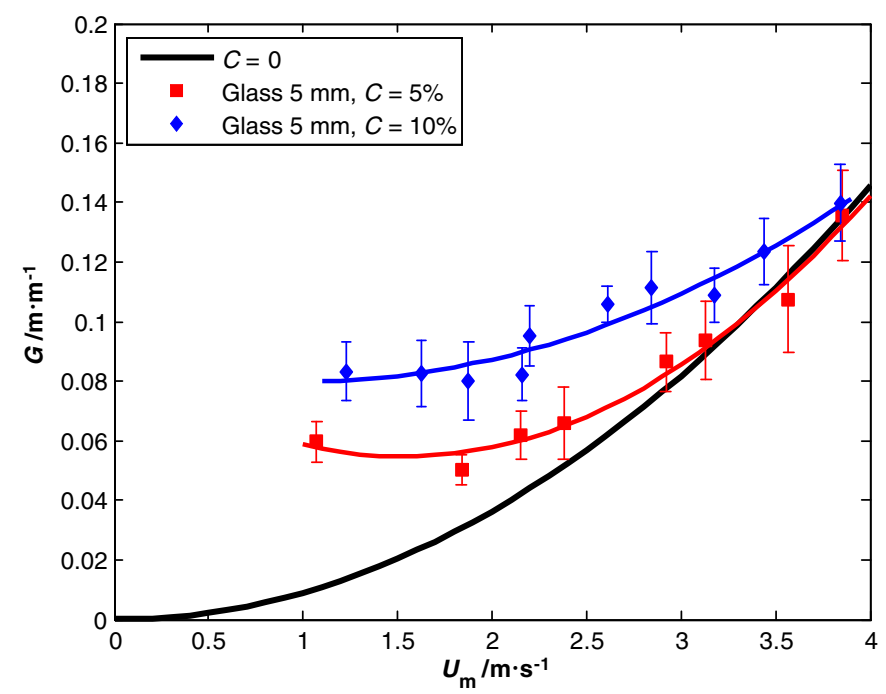

Fig. 6. Hydraulic gradient versus speed mixture. Glass's concentration effect of $5 \mathrm{~mm}$ size.

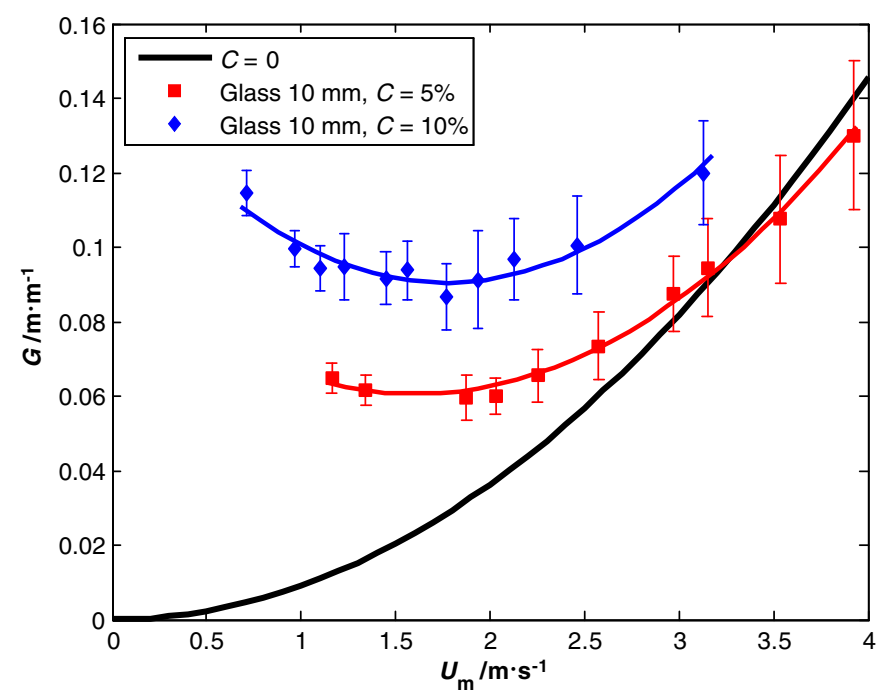

Fig. 7. Hydraulic gradient versus speed mixture. Glass's concentration effect of $10 \mathrm{~mm}$ size.

\subsection{Density effects}

Figs. 8 and 9 show experimental measurements of the pressure drop for the two types of solids (alumina and glass) with almost similar size $\left(d_{\mathrm{p}} \simeq 5 \mathrm{~mm}\right)$ and two different densities, respectively $\rho_{\mathrm{al}}=$ $3650 \mathrm{~kg} \cdot \mathrm{m}^{-3}$ and $\rho_{\mathrm{G}}=2500 \mathrm{~kg} \cdot \mathrm{m}^{-3}$ for two different concentrations, respectively $C=5 \%$ and $C=10 \%$.

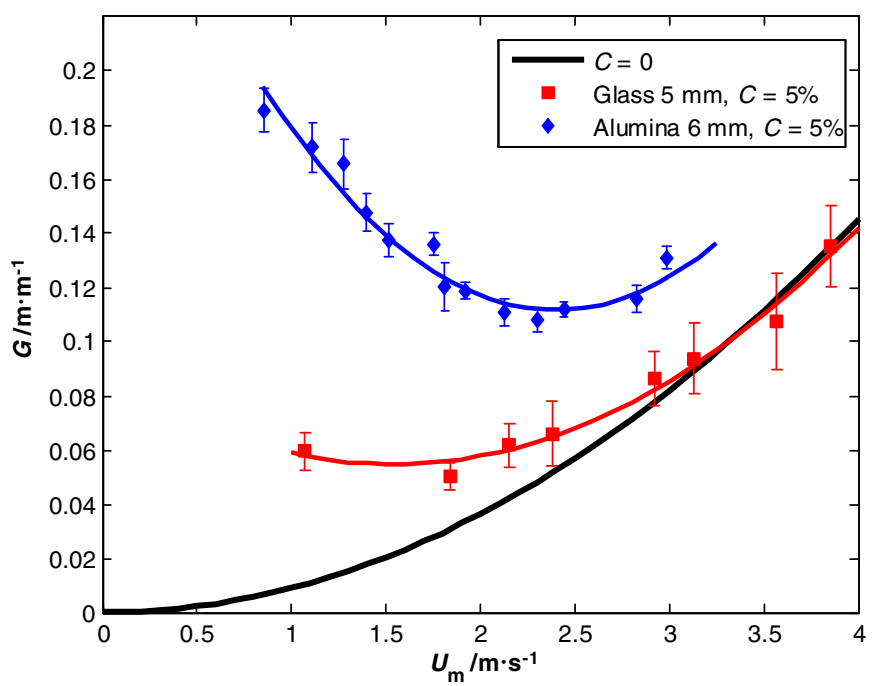

Fig. 8. Hydraulic gradient versus speed mixture. Density effect for $C=5 \%$.

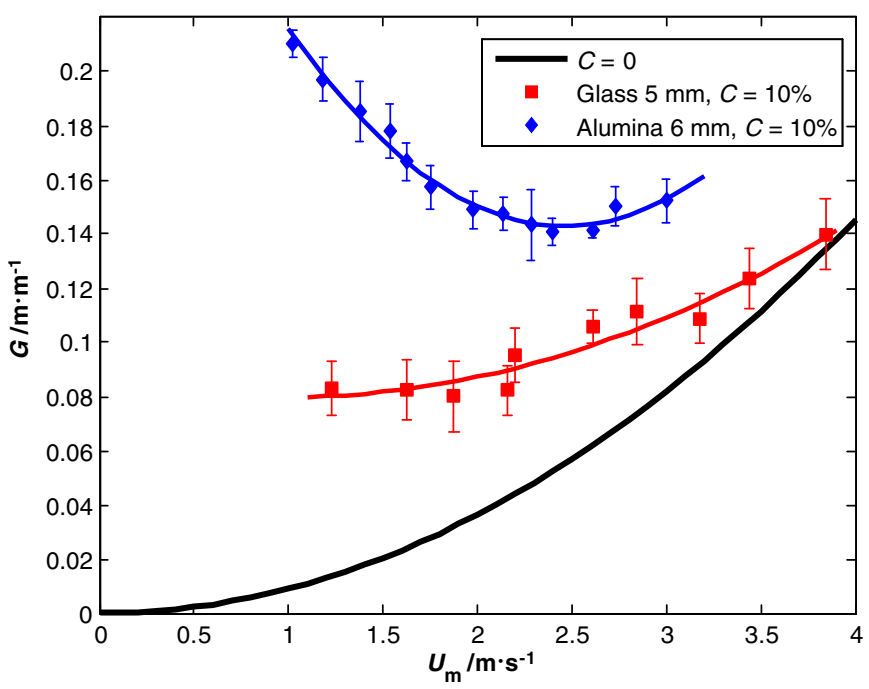

Fig. 9. Hydraulic gradient versus speed mixture. Density effect for $C=10 \%$.

We note that the increase in density leads to a considerable increase in the pressure loss and the critical speed. The shape of these curves is very similar to the work of Newitt et al. [12], Doron et al. [4], and Ravelet et al. [11].

\subsection{Size effects}

To illustrate the effect of the size on the solid particles on the pressure drop we take the same types of particles (density) with the same concentration. Figs. 10 and 11 show the alumina size effect on the hydraulic gradient with, respectively, $5 \%$ and $10 \%$ of concentration. 


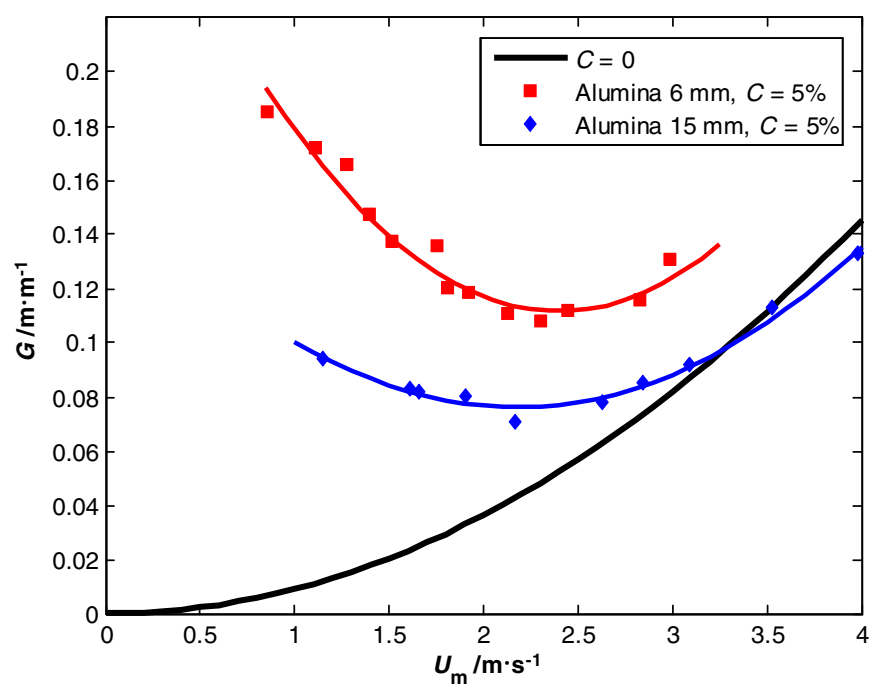

Fig. 10. Hydraulic gradient versus speed mixture. Alumina's size effect with $C=5 \%$.

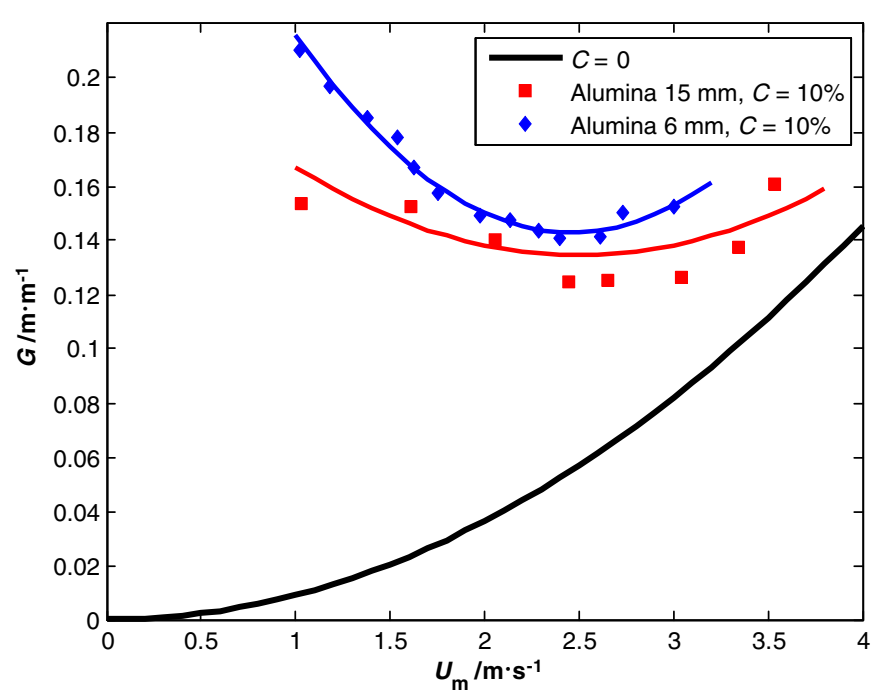

Fig. 11. Hydraulic gradient versus speed mixture. Alumina's size effect with $C=10 \%$.

Figs. 12 and 13 show the glass bead size effect on the hydraulic gradient with, respectively, $5 \%$ and $10 \%$ of concentration.

We perform the comparison of the two sizes of beads with same specific mass at the same concentration, and we observe that the effects of the alumina size on the pressure drop are to decrease by large particles. However, the critical velocity does not seem to be affected by the particle size. Such behavior is found in the results of Ravelet et al. [11]. We notice that this outcome has not been reported in previous works, mainly dealing with particles below $4 \mathrm{~mm}$. On the other hand, we can't confirm this result for the glass particles (Figs. 12 and 13).

\section{Conclusions}

In this work, the water/solid particle flow inside a pipe was visualized and measured pressure drop as a function of the solid-liquid mixture speed studied. Calibrated beads of alumina and glass with different sizes and densities were used. The particles are relatively large with

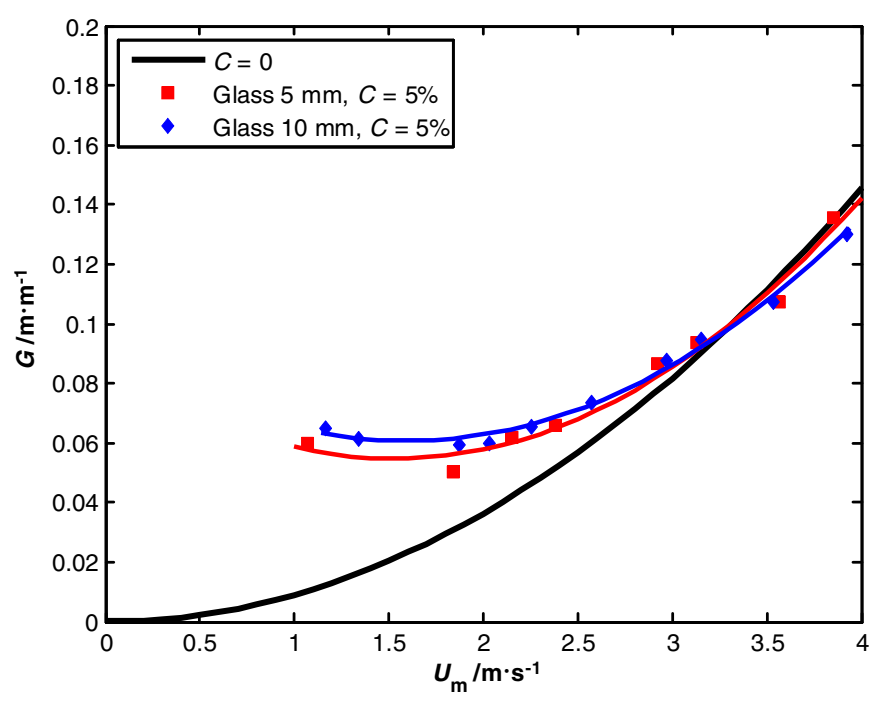

Fig. 12. Hydraulic gradient versus speed mixture. Glass's size effect with $C=5 \%$.

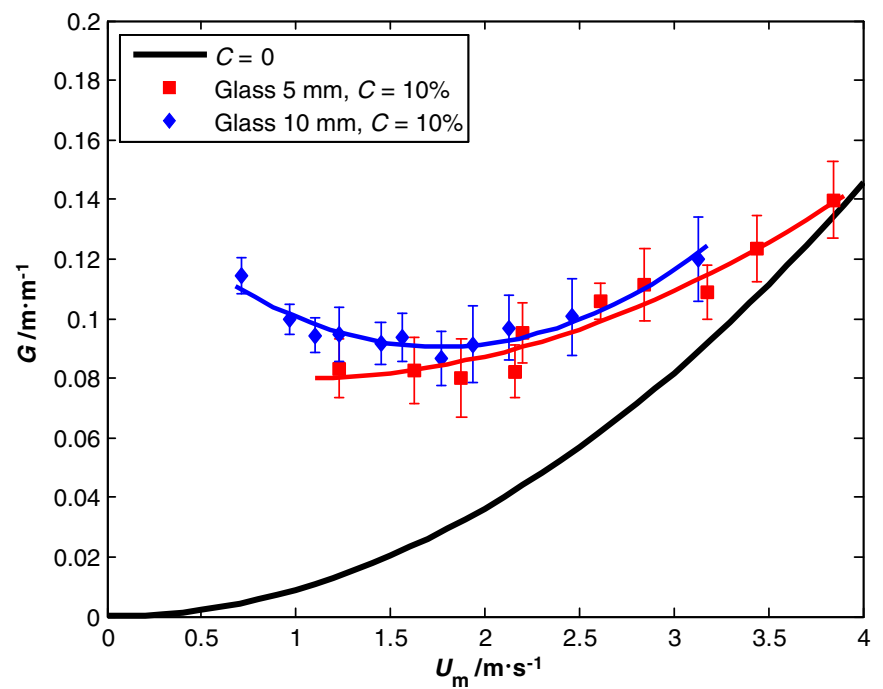

Fig. 13. Hydraulic gradient versus speed mixture. Glass's size effect with $C=10 \%$.

sizes between $8 \%$ and $25 \%$ of the pipe diameter. The main results are summarized below:

- The pressure drop is higher with solid particles.

- For $U_{\mathrm{m}}<U_{\mathrm{c}}$, a flow regime with a stationary bed is observed and above this bed is flowing a ball-compact layer. As a result, the pressure drop increases.

- When $U_{\mathrm{m}}>U_{\mathrm{c}}$, the particles are kept in suspension and the pressure drop curves follow the trend of clear water curve. We observe a pseudo-homogeneous dispersed flow.

- Around the critical velocity $U_{c}$, a separate flow regime with a compact moving bed is noted.

- When the concentration increases, the pressure drop increases and the critical speed increases slightly.

- The pressure drop and the critical velocity increase when the density increases. The density has a strong effect on the transition point between the stationary bed flow and the dispersed flow.

- The hydraulic gradient decreases with an increase in the alumina particle size in a horizontal pipe for a given specific mass and 
concentration. However, for glass particles, the result is not confirmed yet.

The obtained data are so difficult to model because of many factors affecting the pressure drop and their relative importance varies drastically with the velocity. The efforts are to be devoted to establishing reliable pressure drop correlations.

\section{Nomenclature}

C solid concentration, \%

D tube diameter, $\mathrm{m}$

$d_{\mathrm{p}} \quad$ particle diameter, $\mathrm{m}$

$G \quad$ hydraulic gradient, $m_{\text {water column }} / m_{\text {pipe }}$

$G_{\mathrm{c}} \quad$ critical hydraulic gradient, $m_{\text {water column }} / m_{\text {pipe }}$

g gravity, $\mathrm{m} \cdot \mathrm{s}^{-2}$

$L \quad$ distance between the pressure taps, $m$

$Q_{l} \quad$ volumetric flow rates of the liquid, $\mathrm{m}^{3} \cdot \mathrm{s}^{-1}$

$Q_{s} \quad$ volumetric flow rates of the solid, $\mathrm{m}^{3} \cdot \mathrm{s}^{-1}$

$U_{\mathrm{c}} \quad$ critical velocity, $\mathrm{m} \cdot \mathrm{s}^{-1}$

$U_{\mathrm{m}} \quad$ mixture velocity, $\mathrm{m} \cdot \mathrm{s}^{-1}$

$\Delta P \quad$ pressure drop measured, $\operatorname{bar}\left(1 \mathrm{bar}=10^{5} \mathrm{~Pa}\right)$

$\lambda \quad$ friction coefficient

$\rho_{\mathrm{Al}} \quad$ alumina density, $\mathrm{kg} \cdot \mathrm{m}^{-3}$

$\rho_{\mathrm{e}} \quad$ liquid density, $\mathrm{kg} \cdot \mathrm{m}^{-3}$

$\rho_{\mathrm{G}} \quad$ glass density, $\mathrm{kg} \cdot \mathrm{m}^{-3}$

\section{Acknowledgments}

This research was supported by the DynFluid Laboratory at Arts et Métiers Paris Tech. We would like to express our gratitude to Pr. Farid BAKIR for his assistance in the design and development of the experiment.

\section{References}

[1] P. Doron, D. Barnea, Flow pattern maps for solid-liquid flow in pipes, Int. J. Multiphase Flow 22 (1996) 273-283.

[2] I. Zandi, Hydraulic transport of bulky materials, in: I. Zandi (Ed.), Advances in solidliquid flow in pipes and its applications, Pergamon Press, Oxford 1971, pp. 1-34.

[3] R.M. Turian, T.F. Yuan, Flow of slurries in pipelines, AIChE Journal 23 (1977) 232-243.
[4] P. Doron, D. Granica, D. Barnea, Slurry flow in horizontal pipes, experimental and modeling, Int. J. Multiphase Flow 13 (4) (1987) 535-547.

[5] P. Doron, D. Barnea, A three layer model for solid liquid flow in horizontal pipes, Int. J. Multiphase Flow 19 (6) (1993) 1029-1043.

[6] K.C. Wilson, F.J. Pugh, Dispersive-force modeling of turbulent suspension in heterogeneous slurry flow, Can. J. Chem. Eng. 66 (1988) 721-727.

[7] V. Matousek, Flow mechanism of sand/water mixtures in pipelines(PhD Thesis) Delft University of Technology, Delft, Netherlands, 1997.

[8] O. Bratland, Pipe Flow 2, Multiphase Flow Assurance, Electronic book, www. drbratland.com/PipeFlow2/index.html 2010.

[9] S.K. Lahiri, K.C. Ghanta, Prediction of pressure drop of slurry flow in pipeline by hybrid support vector regression and genetic algorithm model, Chin. J. Chem. Eng. 16 (6) (2008) 841-848.

[10] D. Edelin, P.C. Czujko, C. Castelain, C. Josset, F. Fayolle, Experimental determination of the energy optimum for the transport of floating particles in pipes, Exp. Thermal Fluid Sci. 68 (2015) 634-643.

[11] F. Ravelet, F. Bakir, S. Khelladi, R. Rey, Experimental study of hydraulic transport of large particles in horizontal pipes, Exp. Thermal Fluid Sci. 45 (2013) 87-197.

[12] D.M. Newitt, M.C. Richardson, M. Abbott, R.B. Turtle, Hydraulic conveying of solids in horizontal pipes, Trans. Inst. Chem. Eng. 33 (1955) 93-113.

[13] J.F. Richardson, W.N. Zaki, Sedimentation and fluidisation, Trans. Inst. Chem. Eng. 32 (1957) 35-53.

[14] J.X. Xia, J.R. Ni, C. Mendoza, Hydraulic lifting of manganese nodules through a riser J. Offshore Mech. Arct. Eng. 126 (1) (2004) 72-77.

[15] C.H. Yoon, J.S. Kang, Y.C. Park, Y.J. Kim, J.M. Park, S.K. Kwon, Solid-liquid flow experiment with real and artificial manganese nodules in flexible hoses, Proceedings of the Eighteenth International Offshore and Polar Engineering Conference, Vancouver, Canada 2008, pp. 68-72.

[16] H.A. Babcock, The sliding bed flow regime, Hydrotransport I. Proceedings of the First International Conference on the Hydraulics of Transport of Solids in Pipes, Coventry, England, 1970.

[17] M. Toda, H. Konno, S. Saito, Simulation of limit-deposit velocity in horizontal liquidsolid flow, Proceedings of the Seventh International Conference on the Hydraulic Transport of Solids in Pipes, Sendai, Japan, Paper J2 1980, pp. 347-358.

[18] G.A. Wani, Critical velocity in multisize particle transport through pipes, Chapter 4 in encyclopedia of fluid mechanics, vol. 5, Slurry Flow Technology, Gulf Publishing Company, Book Division, 1986.

[19] J.W. Hayden, T.E. Stelson, Hydraulic conveyance of solids in pipes, in: I. Zandi (Ed.), Advances in solid-liquid flow in pipes and its applications, Pergamon Press, Oxford 1971, pp. 149-163.

[20] R.M. Turian, T.F. Yuan, Flow of slurries in pipelines, AICHE J. 23 (1977) 232-243.

[21] P.E. Baha Abulnaga, Slurry systems, handbook, McGraw-Hill, 2002 4.1-4.66.

[22] S.A. Miedema, An overview of theories describing head losses in slurry transport: A tribute to some of the early researchers, ASME 32nd International Conference on Ocean, Offshore and Arctic Engineering, ASME, 2013 (V04AT04A038).

[23] S.A. Miedema, A head loss model for slurry transport in the heterogeneous regime Ocean Eng. 106 (2015) 360-370.

[24] R. Durand, E. Condolios, Etude expérimentale du refoulement des matériaux en conduites en particulier des produits de dragage et des schlamms, Deuxièmes Journées de l'Hydraulique (Grenoble) 1952, pp. 27-55. 